IBIMA Publishing

Journal of Eastern Europe Research in Business \& Economics http://www.ibimapublishing.com/journals/JEERBE/jeerbe.html

Vol. 2013 (2013), Article ID 923384, 13 pages

DOI: $10.5171 / 2013.923384$

Research Article

\title{
Motivation in the Context of Global Economic Crisis
}

\author{
Ion Popa and Doina I. Popescu
}

The Bucharest University of Economic Studies, Bucharest, Romania

Received 30 March 2012; Accepted 29 April 2012; Published 19 May 2013

Copyright (C) 2013 Ion Popa and Doina I. Popescu. Distributed under Creative Commons CC-BY 3.0

\begin{abstract}
The article presents motivation techniques that can help managers achieve the performance they desire in context of global economic crisis. So, is analyzed some newer, yet largely untested, motivation forms that managers are experimenting with.

The analysis was performed through a study that aims to highlight the attempts made in the adoption of newer forms of motivation in the clothing industry in Romania and future directions in this field.
\end{abstract}

Keywords: Newer motivation forms, innovation, Romanian clothing industry, global economic crisis.

\section{Introduction}

This article aims to analyze the literature findings and development regarding to innovative reward systems and apply those findings to Romanian apparel companies to see how well they fit or not to the specifics of this industry in order to maintain and attract human resources. The apparel companies in the Romanian industry is facing a labor shortage, but also a lack of qualified staff. The study confirms the need for innovative reward systems for maintaining and attracting human resources, but it also increases the competitiveness of firms. The study shows the need and opportunity to introduce three of the six systems, namely those that match the specific of the apparel industry.

\section{Methodology}

The study was started with the review of literature and theories of human resource management, namely the theories related to innovative reward systems, and of organizational behavior. Since the apparel industry in Romania is a branch with an old tradition in export of a diverse assortment, ranking third place in Romania's exports, and fourth place in the EU clothing exports and concentrating the larges number of SME's in the industry we felt it was a representative industry in identifying the most appropriate reward innovative systems adapted to this industry. For this we conducted a questionnaire-based investigation with a number of 243 companies from the Romanian apparel industry from all developed regions of the country. Six innovative reward systems, presented in the literature, were analyzed and the extent to which they can be implemented in these companies. We consider that our research is necessary, given the effects of world economic crisis on human motivation in conjunction with labor migration. 


\section{Innovative Reward Systems}

To obtain (and retain) a high-performing workforce, an enterprise must develop a well-conceived compensation program. In this respect, an enterprise may choose one of the newer and innovative reward programs. So, in addition to standard organizational rewards such as pay, fringe benefits, advancement, and opportunities for growth, some organizations are experimenting with more innovative reward programs. Six different approaches to such rewards that are not widely tested are Skill-Based Pay, Team-Based Rewards, Banking Time Off, The All-Salaried Team, Gainsharing, and Employee Stock Ownership Plans (Ivancevich, Konopaske, Matteson, 2007).

Promotions, increased pay, recognition for a job well done, or the opportunity to own a part of an organization can be motivators if there is a clear line of sight between what the employee is doing and the reward. Line of sight means that the employee perceive that there is a "real" linkage between his or her performance and the rewards received. In the case of extrinsic rewards, organizations need to have systems that clearly tie rewards to desired performance. Gainsharing, Stock options, and other extrinsic systems must be built around the line-of-sight concept. Unfortunately, accomplishing a clear line of sight is difficult. Merit-Pay systems claim that they reward performance. Unfortunately, despite the notion of merit, employees do not always see or perceive the connection between rewards and performance. The practice of pay secrecy suggests that line of sight is difficult to achieve. Secret pay actions cloud up any line-of-sight effort. (Ivancevich, Matteson, 1999).

\section{Skill-Based Pay}

Skill-Based Pay is being used by a growing number of firms. In traditional compensation systems, workers are paid on the basis of their jobs. The hourly wage rate depends primarily on the job performed. In a skill-based plan, employees are paid at a rate based on their personal skills. Typically, employees start at a basic initial rate of pay and they receive increases as their skills develop. Their pay rates are based on skill levels, no matter which jobs they are assigned.

In conventional pay systems, the job determines the pay rate and range. In the skill-based plan, the skills developed by employees are the key pay determinants. The skill-based pay plan approximates how professionals are compensated. In many organizations, professionals who do similar work are difficult to separate in terms of contributions made. In skill-based plans, pay increases are not given at any specific time because of seniority. Instead, a raise is granted when employees demonstrate their skills to perform particular jobs.

Skill-based pay systems have at least four potential advantages (Hills, Bergman, Scarpello, 1994):

- Since employees have more skills the organization increases its flexibility by assigning workers to different jobs;

- Because pay is not determined on the basis of the classification to which the job is assigned, the organization may need fewer distinct job classifications;

- Fewer employees are needed because more workers are interchangeable;

- The organization may experience reductions in turnover and absenteeism.

In the human resource management, competency/ skill has two meanings: personal competence (behavioral) and competent work (occupational).

Personal skills (behavioral) are represented by the personal characteristics of an occupant of the post, which he uses in carrying out work roles.

Work skills (occupational) refer to the professional performance expectations, i.e. what they need employees to be able to do, and the standards and concrete results that those who meet certain specified roles must reach. 
The competency/skill concept was popularized for the first time by Boyatzis in the 80's (Armstrong, 2003). He developed this concept from research that established that no single factor, but a sum of factors that distinguish effective employees from less effective ones. The range of these factors entering personal qualities, motives, experience and behavioral characteristics shared by various categories. Boyatzis defined the personal competence as "an interior capacity thanks to which the person has a behavior likely to meet the job requirements to work within the parameters of organizational environment, which leads to desired results." Subsequently, the competency/ skill has seen different approaches and therefore theorists have assigned several meanings, depending on how it can be applied.

There are different approaches regarding the components of competency/ skill. Some argue that this concept symbolizes the behavior of individuals to fulfill their functions and knowledge and skills that influence or determine this behavior. There are also several types of skills. They can be generic or specific, to the borderline or of performance, or of difference:

- Generic skills are valid for all people with the same occupation or same job, regardless of the company which owns or the particular role they fulfill. Also, they can be generic and at an organizational level, valid for all staff in a firm;

- Specific skills are those of individual roles necessary to fulfill a specific task;

- The borderline skills are the minimum necessary to execute the task, which does not distinguish between high performers and low ones. Performance skills make this distinction;

- Differentiating competencies define the behavioral characteristics that high performers display unlike those that characterize people less effective.
As a conclusion, Michael Armstrong (2003) makes this list of the most significant meanings of Competency / Personal skills:

- Behavioral dimensions that affect professional performance;

- Any individual characteristic that can be measured or counted as a minimum margin of error which can be shown to cause significant differences between effective and ineffective performance;

- Endowments and fundamental capabilities needed for successful completion of the task;

- All attributes, knowledge, skills and personal values relating to employment of a person is used to make a good job;

- The fundamental characteristic of a person that results in effective or superior performance.

\section{Team-Based Rewards}

Individual pay-for-performance reward systems do not properly fit an organization that is designed around or uses teams because this system put individuals who need to cooperate under a reward system that fosters competition. Teams need to cooperate within the team structure and process. It is still difficult in a country that prides itself on individualism to convince employees to work together, to trust each other, and to be committed to group goals above individual work-related goals.. People who value individualism become worried and skeptical about the so-called freeloader who does not perform well but gets the same rewards as everyone else. (Neuforne, 1997). On the other hand, there are ways to encourage poor performers to improve or leave. There are also methods to give special recognition and show respect to outstanding team leaders and performers (Lawler, 1996).

Interact and Gallup Romania conducted a national survey (conducted in January 2005 and published in the April 18, 2005) 
the implications of Romanian values and behavior upon management practices from the perspective of cultural dimensions by Geert Hofstede's method. The study showed that Romania has similar values with other Balkan countries (Greece, Bulgaria, Serbia) namely remoteness from authority, collectivism (low degree of individualism), femininity, high uncertainty avoidance and short-term orientation. Regarding the level of individualism, the Romanian population indicated 49 on a scale of $0-100$, where 100 means high individualism and numbers below 50 indicate a collectivist society. Most of the world population lives in collectivist societies, only a few countries have high values individualism, such as the United States which have the highest values (91). Collectivist values of a nation's wealth are a barometer for a country, because individualism indicates the need for selfaffirmation and financial independence of the public.

In collectivist countries, individuals are subject to the rules of the social group they belong to and society is fragmented into several such groups, united by common interests. The groups promote their members' interests at the expense of other groups, "us" against" you".

The degree of individualism of the population is increasing due to the correlation identified by Hofstede (2004) between individualism and funding received by that country. The degree in which a country is supplied with external funding is the level of individualism and hence confidence in the individual ability to create increased added value. (The study on the implications of Romanian values and behavior upon management practices from the perspective of cultural dimensions by Geert Hofstede's method, 2005).

The design of a team based reward system should follow the grouping in the overall organizational design. In situations where teams are relatively independent and measurable goals can be set and evaluated, rewards can be based on goal accomplishment.
In situation where teams are interdependent on each other, a plant, division or area reward plan may be the best system. Management must carefully analyze the independenceinterdependence conditions.

The challenges of rewarding project teams are somewhat different. Since project team performance is usually short term and a one-time occurrence, it seems more appropriate to provide members with bonuses instead of permanent base-pay merit rewards.

\section{Banking Time off}

Time off from work is attractive to most people. In essence, most companies have a time-off system built into their vacation programs. Employees receive different amounts of time off based on the years they have work for the organization. An extension of such a time-off reward could be granted for certain levels of performance. That is, a bank of time-off credits could be built up contingent on performance achievement.

Today, some organizations are selecting their best performers to attend educational and training programs. So, this organizations selects the best performers and provide them with an opportunity to attend education and training programs. Being eligible is largely contingent on the performance record of the individual. Those finally selected are given two days off (Fridays for example) a month to attend classes.

\section{The All-Salaried Team}

In most organizations, managers are paid salaries, and non managers receive hourly wages. The practice of paying all employees a salary is supposed to improve loyalty, commitment, and self-esteem. The notion of being a part of a team is projected by the salary-for-everyone practice. To date, rigorous investigations of the influence, if any, of the all-salary practice are not available. 


\section{Gainsharing}

Gainsharing plans provide employees with a share of the financial benefits the organization accrues from improved operating efficiencies and effectiveness. (Blackburn, Rosen, 1993). Probably the best-known example of gainsharing is the Scanlon Plan, named after its developer, Joseph Scanlon. A typical Scanlon Plan measures the labor costs required to produce goods or services during a base period. If future labor costs are less, a portion of the savings realized is shared with the employees responsible for the cost savings. In some companies, bonuses paid to workers under a Scanlon Plan can equal or exceed the employees usual salary. Scanlon Plan companies typically rely on elaborate suggestion systems for receiving employee recommendations for operating efficiencies.

In a typical gainsharing plan, an organization uses a formula to share financial gains with all employees in a single plant or location (Wilson, 1996). The organization establishes a historical base period of performance and uses this to determine whether or not gains in performance have occurred. Typically, only controllable costs are measured for the purpose of computing the gain. Unless a major change occurs in the organization's products or technology, the historical base figure stays the same over the duration of the plan. The organization's performance is always compared to the time period before it implemented the gainsharing plan.

Gainsharing can take many forms. Simple cash awards for suggestions that are implemented is a form of gainsharing. Virtually any program that shares cost reductions with employees may be considered gainsharing.

Successful gainsharing programs require a strong commitment to operating efficiencies from both management and employees. In turn, such a commitment requires open communications, information sharing, and high levels of trust between all parties.

\section{Employee Stock Ownership Plans}

ESOPs, as employee stock ownership plans are commonly called, are somewhat like gainsharing plans, a form of group incentive. Under ESOPs, companies make contributions of stock (or cash to purchase stock) to employees. Typically, but not always, individual employee allocation is based upon seniority. ESOPs can provide a substantial nest egg for employees upon retiring or leaving the company. Organizations can benefit from improved performance from employees who now have a very direct financial stake in the company. The companies which applied ESOPs offers stock with discount, and usually the goal of the plan is to provide no more 25 percent employee ownership.

Research on the effectiveness of employee stock ownership plans is mixed. Like any other reward system results will vary as a function of how well management introduces and implements the plan. Administering rewards is perhaps one of the most challenging and frustrating tasks that managers must perform.

\section{Study on the Examination of the Reward Systems Used and State of Adoption of Innovative Reward Systems in the Romanian Apparel Companies}

In this research we intend to bring an important contribution in terms of both theoretical and pragmatic aspects, in the studied field. The need of examining the specifics of reward systems and the adoption stage of innovative reward systems (presented in the paper) in Romania is justified by the fact that the apparel industry is most affected by labor shortages. Thus, Romania is mainly a labor exporting country (according to National Institute of Statistics, in 2010 approximately 2 million people working abroad). Also, although the educational system for apparel industry in Romania has five academic centers (in Iasi, Sibiu, Arad, Oradea and Bucharest), research and development institutes, training centers for craftsmen and technicians, the number of graduates of these schools is increasingly 
small, revealing low attractiveness for jobs related to this industry.

We consider, in this context, that measures are needed to maintain and attract labor force in companies belonging to one of the most important industries in Romania. In addition, the number of orders in lohn system for Romania (the main processing system in the Romanian apparel industry) increased due to political instability in countries of North Africa. These countries managed, until recently, to attract more orders because of lower labor costs than the labor costs in Romania.

This research aims at four objectives:

Objective 1: Identifying the production features influencing the reward systems used in the apparel industry;

Objective 2: Identifying the reward systems currently used by clothing companies;

Objective 3: Identifying the current state of adoption of innovative reward systems by the surveyed companies;

Objective 4: Identifying the most appropriate reward innovative systems adapted to the particularities of Romanian apparel industry and the future expansion directions of their use.

The investigation identified a number of major obstacles in achieving the research objectives, including:

- Lack of significant research in Romania and abroad;

- Lack of adequate knowledge in the organizations surveyed to support research;

- Increased reluctance among representatives of the companies analyzed to provide data related to them.
The questions were structured in three thematic modules:

I. General information about the analyzed companies

This section includes general identification questions, address, development region of which the company belongs to, of establishing the size of the company by the number of employees, and the capital type.

II. Information about the reward systems currently used by companies

The set of questions used in this section serves the direct purpose of research, questions intended to identify the respondents' opinion on the importance of using innovative reward systems appropriate for Romanian apparel industry, appropriate for the current socioeconomic context, identifying the specific forms of reward used, and also their correlation with firm size, the development region which belongs, difficulty adopting innovative reward systems.

III. Future directions to extend the use of innovative reward systems in the apparel industry

This section is very important because it presents directions for future enlargement of the number of clothing companies that use innovative reward systems.

The research was designed, conducted and analyzed by the authors.

\section{The Sample of Firms Investigated}

The questionnaire-based study (Appendix) was conducted on a number of 243 apparel companies (men and women clothing) of all development regions in Romania and refers to the year 2011. Details of the territorial structure of the sample of firms investigated are presented in Table 1. 
Table 1. Distribution of the Sample by Development Regions

\begin{tabular}{|c|c|c|c|}
\hline No. Crt. & Development region & $\begin{array}{c}\text { No. Of analyzed } \\
\text { firms }\end{array}$ & Percentage (\%) \\
\hline 1 & North-West & 34 & 13,99 \\
\hline 2 & North-East & 39 & 16,05 \\
\hline 3 & West & 24 & 9,88 \\
\hline 4 & Center & 40 & 16,46 \\
\hline 5 & South-West & 20 & 8,23 \\
\hline 6 & South-East & 30 & 12,35 \\
\hline 8 & South & 32 & 13,17 \\
\hline 9 & Bucharest and Ilfov & 24 & 9,87 \\
\hline Total & & $\mathbf{2 4 3}$ & $\mathbf{1 0 0}$ \\
\hline
\end{tabular}

\section{Presentation of General Information about the Sample Firms}

By the capital type, of the 243 firms, 44 are joint-ventures with foreign capital, 199 are ventures with local capital (Figure 1).

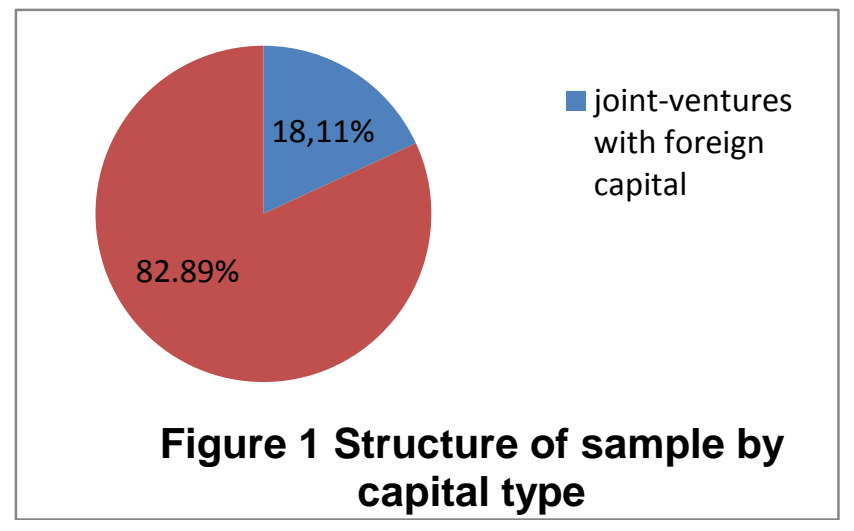

Structure of firms by number of employees is presented in Table 2 .

Table 2. Structure of Firms by Number of Employees

\begin{tabular}{|c|c|c|c|c|}
\hline Total & $\begin{array}{c}\text { Large (over 250 } \\
\text { employees) }\end{array}$ & $\begin{array}{c}\text { Medium (50- } \\
249 \text { employees) }\end{array}$ & $\begin{array}{c}\text { Small (10-49 } \\
\text { employees) }\end{array}$ & $\begin{array}{c}\text { Micro (1-9 } \\
\text { employees) }\end{array}$ \\
\hline 243 & 5 & 32 & 77 & 129 \\
\hline
\end{tabular}

It is noted that the share of micro firms in the sample analyzed is $53.08 \%, 31.69 \%$ small firms, medium firms $13.17 \%$ and 2.06\% large firms (Figure 2). 


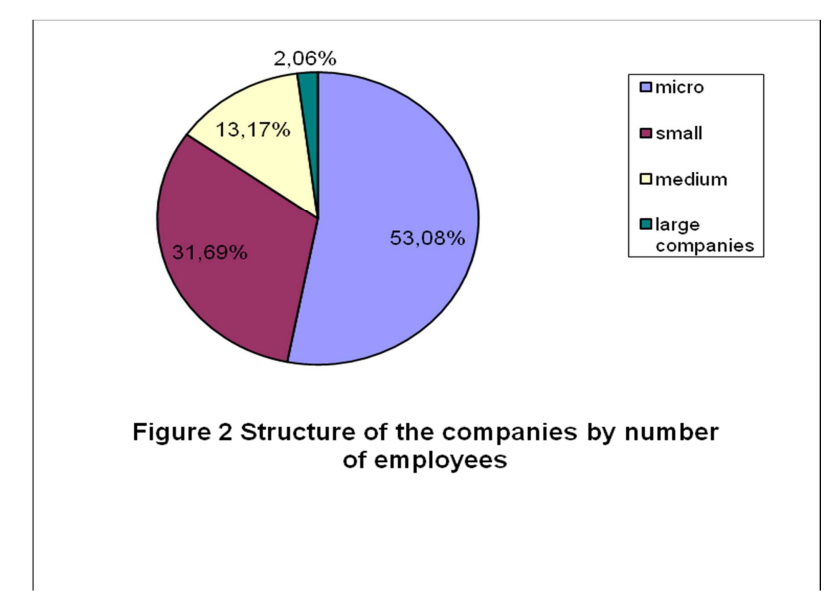

II. On matters related to the use of innovative reward systems in the companies analyzed, the responses revealed the following:

- Managers of companies think that only 2 of the 6 innovative reward systems (presented in the questionnaire) are work-appropriate to the clothing companies in Romania, that are SkillBased Pay and Time Off Banking systems, which otherwise are used;

- A relatively low number of firms that use Skill-Based Pay, and even fewer of those who use Time Banking Off;

- A large number of managers who do not know the innovative reward systems presented;

- Relatively insignificant interest of managers of firms analyzed to try to use Gainsharing.

It is clear that to maintain and attract labor force, managers and owners (shareholders) should be aware of the need to call the new forms of reward instead of the traditional or combined with traditional ones.

The extent to which they expressed agreement with the understanding that "the adoption of innovative reward systems suitable to specific of Romanian apparel industry is one factor that ensures maintaining and attracting labor force" is given in Figure 3.

The results reveal the following:

- $36 \%$ of respondents agree with the above statement, in clear terms or less categorical (total or partial agreement);

- $60 \%$ disagree with the statement made (strongly disagree or partially);

- 4\% do not express an opinion.

From the feedback we note that most managers investigated do not appreciate the role and the importance of adopting innovative reward systems for their organizations. 


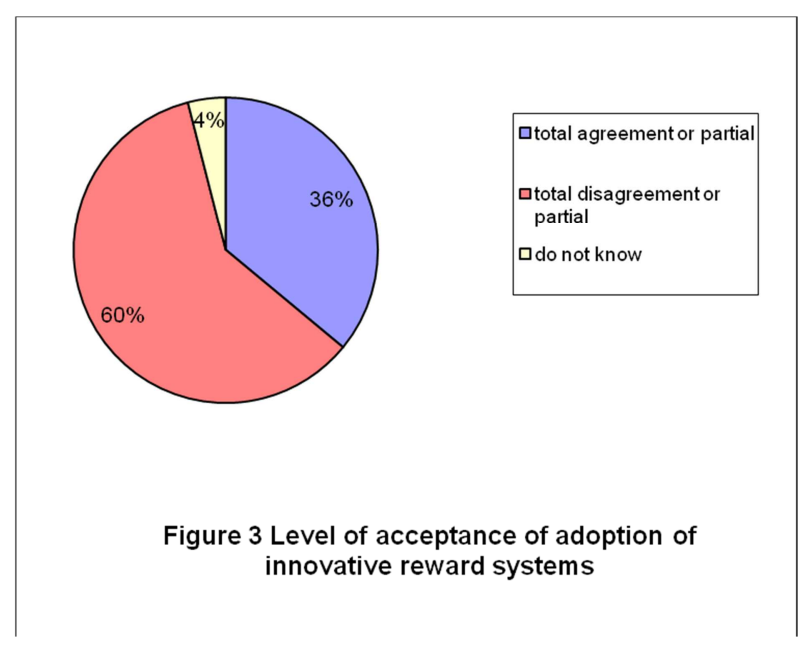

Table 3. Correlative Analysis of Awareness of the Need to Adopt Innovative Reward Systems and the Size of Companies Analyzed

\begin{tabular}{|c|c|c|c|c|}
\hline $\begin{array}{c}\text { Responding } \\
\text { companies }\end{array}$ & $\begin{array}{c}\text { Micro } \\
\mathbf{1 2 9}\end{array}$ & $\begin{array}{c}\text { Small } \\
\mathbf{7 7}\end{array}$ & $\begin{array}{c}\text { Medium } \\
\mathbf{3 2}\end{array}$ & $\begin{array}{c}\text { Large } \\
\mathbf{5}\end{array}$ \\
\hline $\begin{array}{c}\text { Total } \\
\text { agreement }\end{array}$ & 10 & 15 & 10 & - \\
\hline $\begin{array}{c}\text { Partial } \\
\text { agreement }\end{array}$ & 15 & 28 & 8 & 2 \\
\hline Do not know & 8 & 2 & - & - \\
\hline $\begin{array}{c}\text { Partial } \\
\text { disagreement }\end{array}$ & 11 & 4 & 8 & 1 \\
\hline $\begin{array}{c}\text { Total } \\
\text { disagreement }\end{array}$ & 85 & 28 & 6 & 1 \\
\hline
\end{tabular}

It stands out that large firms and small and medium especially aware of the need to adopt innovative reward systems, the lowest percentage of registered micro businesses.

Table 4. Correlative Analysis of Awareness of the Need to Adopt Innovative Reward Systems and Development Region of which the Company Belongs

\begin{tabular}{|c|c|c|c|}
\hline No. crt. & $\begin{array}{c}\text { Development } \\
\text { Region }\end{array}$ & $\begin{array}{c}\text { No. of companies } \\
\text { that realize the } \\
\text { need to adopt } \\
\text { innovative reward } \\
\text { systems }\end{array}$ & Percentage (\%) \\
\hline 1 & North-West & 24 & 26,97 \\
\hline 2 & North-East & 8 & 8,99 \\
\hline 3 & West & 18 & 20,22 \\
\hline 4 & Center & 17 & 19,10 \\
\hline 5 & South-West & - & - \\
\hline 6 & South-East & 5 & 4,61 \\
\hline 8 & South & 4 & 14,62 \\
\hline 9 & Bucharest- Ilfov & 13 & $\mathbf{1 0 0}$ \\
\hline Total & & $\mathbf{8 9}$ & \\
\hline
\end{tabular}


It is established that only 89 of the 243 companies realize the need to adopt innovative reward systems. Regarding the development regions, a higher share have the firms in NW and W (24 of 34, respectively 18 of 24), followed by those in the Center 17 of the 24, and 13 of 24 in Bucharest-Ilfov. The companies with small shares are located in the NE, S and SE. It is noted that no company in the SW region is not aware of the need to adopt innovative reward systems

The concrete forms of reward regarding use of the 6 analyzed systems showed the following:

- Skill-Based Pay is used by 68 companies while the vast majority of managers of firms analyzed (236) know this system;

- Team-Based Reward is a system known only by 82 managers in the sample analysis is not used by any company and was identified as a specific system is not suitable work in companies belonging to the industry (not team work in this branch);

- Off Time Banking is a known system of 203 managers analyzed and used by only 17 companies in the 203 ;

- The All-Salaried Team is a system known only by 5 managers in the sample analysis is not used by any company and was identified as a specific system is not suitable work in companies belonging to the industry (not team work in this branch);

- Gainsharing is a system known only by 23 managers in the sample analysis is not used by any company being considered impractical especially in the crisis, except for managers of five firms that have shown interest to try using it;
- Employee Stock Ownership Plans is a known system to most managers (225) of the sample analysis is not used by any company and was identified as unproper with the way of trading of actions in this field. Thus, through the privatization process (MEBO) initiated in 1994 (Law 77/1994) was considered that the best approach is that the stake to belong to small communities (from this point of view the companies in this area are closed).

It stands out that all managers of the 243 companies know the Skill-Based Pay reward system, most of them know Employee Stock Ownership Plans and Banking Time Off systems, 34\% of them know Team-Based Reward System, approximately $10 \%$ of them know Gainsharing system, and only $2 \%$ of them know the system The All-Salaried Team.

It is established that only 85 of the $243 \mathrm{i}$ firms apply two of the innovative systems analyzed, namely 68 apply Skill-Based Pay and 17 companies apply Banking Time Off. The remaining 158 companies apply traditional reward systems (wages and food vouchers, the workers are paid on time). - Figure 4.

The 85 companies that apply the two innovative reward systems are divided by size as follows: 3 large companies, 18 medium companies, 43 small and 21 micro firms, and after the development region as follows: 24 in NW, 18 W, 17 in Center, 13 in Bucharest-Ilfov, 4 in S, 3 in SE, 6 in NE. This distribution indicates a higher capacity coupled with the desire to implement innovative systems to reward of companies that have a higher potential financioar (high share of large enterprises, medium and small) and a higher polarization in regions NW, West, Centre and Bucharest-Ilfov, regions in which exist firms with successful brands, known both in the country but also abroad. 


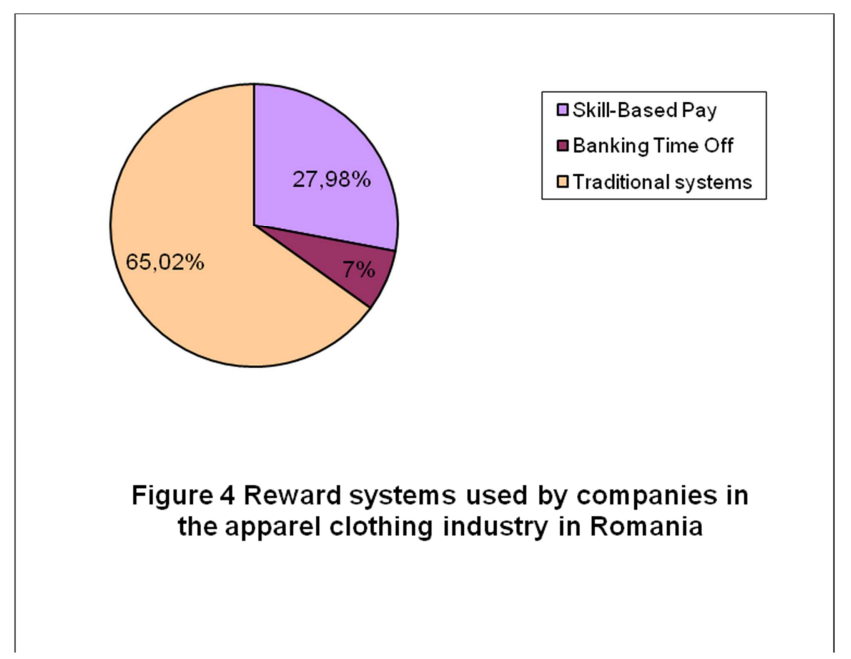

Managers of 85 companies report that after application of the new reward systems, they faced with labor migration to a lesser extent and their employees have improved their performance. In fact, nationally the number of employees grew sensitive for the first time in the last three years, ie 2011 compared to 2010 (Table 5):

Table 5. Number of Employees

\begin{tabular}{|c|c|c|c|}
\hline & Year 2009 & Year 2010 & Year 2011 \\
\hline $\begin{array}{l}\text { Number of } \\
\text { employees }\end{array}$ & 150220 & 141600 & 141700 \\
\hline
\end{tabular}

Source: National Statistics Institute, 2011

Team Based Reward, The All-Salaried Team and Employee Stock Ownership Plans are systems that are not suitable for the specific of apparel industry.

Gainsharing is viewed with skepticism by most of the managers of firms. This attitude is due to the desire to obtain immediate gains, respectively short-term orientation, the value indicated for Romania by the Interact and Gallup Romania study.

III. The future directions to extend the use of innovative reward systems in the apparel industry are:

- Knowledge of innovative reward systems and awareness of the advantages of using them for maintaining and attracting human resources and also for increasing the firms competitiveness;

- Initiating and / or strengthening collaboration with educational institutions offering educational packages and specialized training in order to extend using Skill-Based Pay and Time Off Banking;

- Achievement within organization, (with specialists help and by organizing focus groups and interviews), of a Competency Model in order to be used as a basis for reward;

- Changing the orientation of managers and shareholders from short term to long term, condition for applying the Gainsharing system.

\section{Conclusions}

To maintain and attract human resources and in order to increase competitiveness in the Romanian apparel industry, in the context of global economic crisis and the shortage of labor, use of innovative reward systems represent a viable and necessary solution. Of the six systems of reward presented in the paper results from conceptual developments in the literature, 
three are suitable to particularities of Romanian apparel industry, namely SkillBased Pay, Banking Time Off and Gainsharing. Only the first two systems are applied by some companies (about 35\% of total) on which the study was realized. The study identified future directions to extend the use of innovative reward systems in the apparel industry in Romania.

\section{References}

Blackburn, R. \& Rosen, B. (1993). "Total Quality and Human Resources Management: Lessons Learned from Baldridge Award-winning Companies," Academy of Management Executive.

Hills, F. S., Bergman, T. J. \& Scarpello, V. G. (1994). 'Compensation Decision Making,' The Dryden Press, New York.

Hofstede, G. (2004). Culture, Leadership, and Organizations: The GLOBE Study of 62 Societies (1st ed), Sage Publications.

Ivancevich, J. M., Konopaske, R. \& Matteson, M. T. (2007). Organizational Behavior and Management, Irwin McGraw Hill.

Lawler, E. E. (1996). 'From the Ground Up,' San Francisco: Josey-Bass.

Milkovich, G. T., Ivancevich, J. M., Matteson, M. T., et al. (1999). 'Organizational Behavior and Management,' Irwin McGraw Hill.

Neuforne, E. (1997). 'Companies Save, but Workers Pay,' USA Today.

Wilson, S. Y. (1997). "When is Compensation Not Enough? Rethinking How to Reward the Workforce," Compensation and Benefits Review.

\section{Appendix: Questionnaire}

\section{Section 1. Background}

1. Name of organization:

2. Phone, fax, e-mail:

3. Types of capital: a) Domestic capital

b) Joint venture with foreign capital

4. Number of persons involved (employment):

5. Position (position) within your company

Section 2 - Information: Regarding Use of the Innovative Reward Systems in the Analyzed Companies:

6. Appreciate the following: "adoption of innovative reward systems suitable to the specific Romanian apparel industry is one of the factors that ensures the labor maintenance and attraction" by choosing one of the following:
a). Partial agreement;
b). totally agree;
c). I do not know;
d). partly disagree;
e). strongly disagree.

7. What innovative reward systems are you using?

a). Skill-Based Pay;

b). Team-Based Rewards;

c). Banking Time Off;

d). The All-Salaried Team;

e). Gainsharing;

f). Employee Stock Ownership Plans;

g). Other, namely

h). None of those mentioned.

8). Which of the above reward systems are you unfamiliar with:

a, b, c, d, e, f or a combinations of these

9). If you used one or more of the systems listed above did you manage to maintain 
and / /or to attract human resources within the organization?
a). Yes;
b). No;
c). There was no significant result.

10). Next time, will you use one or more innovative reward systems? If so, which ones?

Comments (if you want to add additional items). 